\title{
An approach towards sustainable passenger mobility in urban areas: a life cycle perspective
}

\author{
H. Dura ${ }^{1} \&$ M. Weil ${ }^{1,2}$ \\ ${ }^{1}$ Institute for Technology Assessment and Systems Analysis (ITAS), \\ Karlsruhe Institute of Technology, Germany \\ ${ }^{2}$ Helmholtz-Institute Ulm for Electrochemical Energy Storage (HIU), \\ Germany
}

\begin{abstract}
Today the high transport demand in urban areas causes high energy consumption and great environmental repercussions such as air and noise pollution, increasing shortage of space, high congestion and traffic jams [1-6]. Numerous studies have already proven that technological improvements alone will not be able to solve all of these problems [7-9]. In order to achieve a more sustainable passenger transportation system the mobility patterns themselves have to undergo certain changes. That goal may be achieved by combining three key elements: (1) technological improvements, (2) user behavior in terms of a modal shift to collective/public or non-motorized transport and (3) user behavior in terms of avoidance of traffic utilizing information and communication technologies (ICT), intelligent transport systems (ITS) and decrease of travel distances [7-9].

A research project is undertaken to quantitatively assess the environmental and economic implications of the three key elements from a life cycle perspective in an urban area. Various means of transportation such as individual vehicular transport as well as public transport using passenger vehicles, trams, subways etc. with electric propulsion system will be considered. The assessment of next generation chemical storage units (batteries, supercapacitors) utilized by the various vehicles will be a large focus.

The presented methodology aims at quantitatively assessing a defined excerpt of future urban mobility in order to analyze the economic and ecological performance of the three key elements one by one and in combination. Thus,
\end{abstract}


pathways towards a more sustainable urban passenger transport will be identified to support decision makers in traffic and mobility management.

Keywords: Life Cycle Assessment, sustainable, passenger transport, prospective, urban, technology, modal shift, transport avoidance.

\section{Introduction}

The environmental burden caused by the transport sector is on a high level and still continues to increase. Despite technological improvements of conventional vehicles, the road transport sector remains one of the largest contributors to air emissions [1] and energy consumption [2]. Particularly densely populated areas largely contribute to the high transport demand and suffer from great environmental repercussions such as air and noise pollution, increasing shortage of space, high congestion and traffic jams [3-6], which in turn lead to external costs that are very hard to evaluate but ultimately have to be carried by society $[7,10,11]$.

Due to all these effects the overall objective is to achieve a state of sustainable transportation. The European Conference of Ministers of Transport (ECMT) [12] has put forth a definition of sustainable transport systems, as one that:

$>$ allows the basic access and development needs of individuals, companies and society to be met safely and in a manner consistent with human and ecosystem health, and promotes equity within and between successive generations.

$>$ Is affordable, operates fairly and efficiently, offers a choice of transport mode and supports a competitive economy, as well as balanced regional development.

Limits emissions and waste within the planet's ability to absorb them, uses renewable resources at or below their rates of generation, and uses non-renewable resources at or below the rates of development of renewable substitutes, while minimizing the impact on the use of land and the generation of noise.

Current studies show, that merely technological improvements will not be able to cope with all of the problems stated above. Generally three key elements may be identified for the employment of a more sustainable transport [7-9, 13] as also depicted in Figure 1 (a) technology, (b) modal shift and (c) reduction of transport volume.

Due to the high importance of mobility in ecological, economic and social terms, particularly in urban areas, political actors are increasingly developing incentives and action plans to promote a more sustainable passenger transport which should predominantly provide mobility and mitigate climate change as well as relieve urban areas of highly congested transport. In order to constructively support the decision process of important stake holders such as urban and transport developers, which combination of the three categories is most viable and how they may be achieved, thorough assessments have to be provided evaluating from a life cycle perspective. 


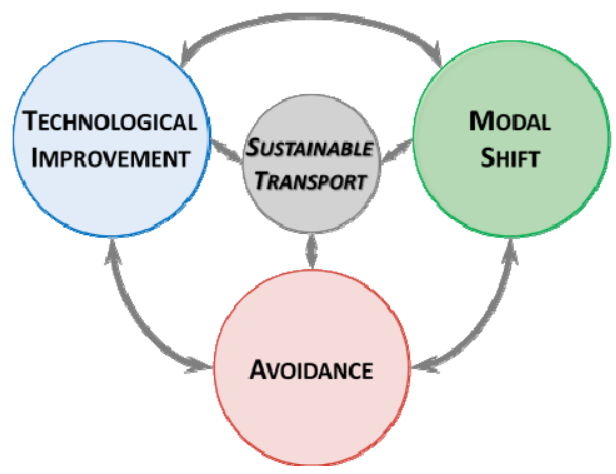

Figure 1: Components of sustainable transport.

\section{Objectives and framework}

The challenge of providing a more sustainable passenger transport requires first of all a number of questions to be answered, beginning with the overarching question: How can the three components (1) technology, (2) modal shift, (3) avoidance contribute to a more sustainable passenger transport in an urban area?

In order to answer this rather broad question a more integrated approach is necessary. Therefore, it is the aim to assess the environmental and economic repercussions of the passenger transport in an urban area, changing one above stated component at a time, to assess their individual contribution. Subsequently the three components will be combined to identify the best possible combination that can reduce the economic and environmental burden of the urban passenger transport. Based on the results of this assessment, decision makers in urban transport planning and management can find supportive answers for their work.

On the components level the technological changes will be great focus, where a number of selected technologies will be compared with each other, in order to find the best technology combinations for specific applications. This in depth assessment may not only provide the urban transport planners and managers with information as to which technologies and schemes may be suitable for e.g. public transport as well as intelligent transport and information and telecommunication technologies. A more detailed explanation is given in section 3.

Figure 2 gives an overview of the system boundaries. Due to the fact that non- motorized passenger traffic has negligible environmental implications merely motorized passenger road transport will be included. The motorized transport modes stated above as well as their necessary infrastructure will be assessed from a life cycle point of view, i.e. the production as well as the use and end of life phase of all transport modes, their infrastructure (e.g. roads, tunnels, charging/refueling infrastructure etc.) as well as fuel production will be included in the analysis. Based on the holistic character of this assessment different technological developments as well as a possible shift in modal split and avoidance of transport will be included in the assessment. 


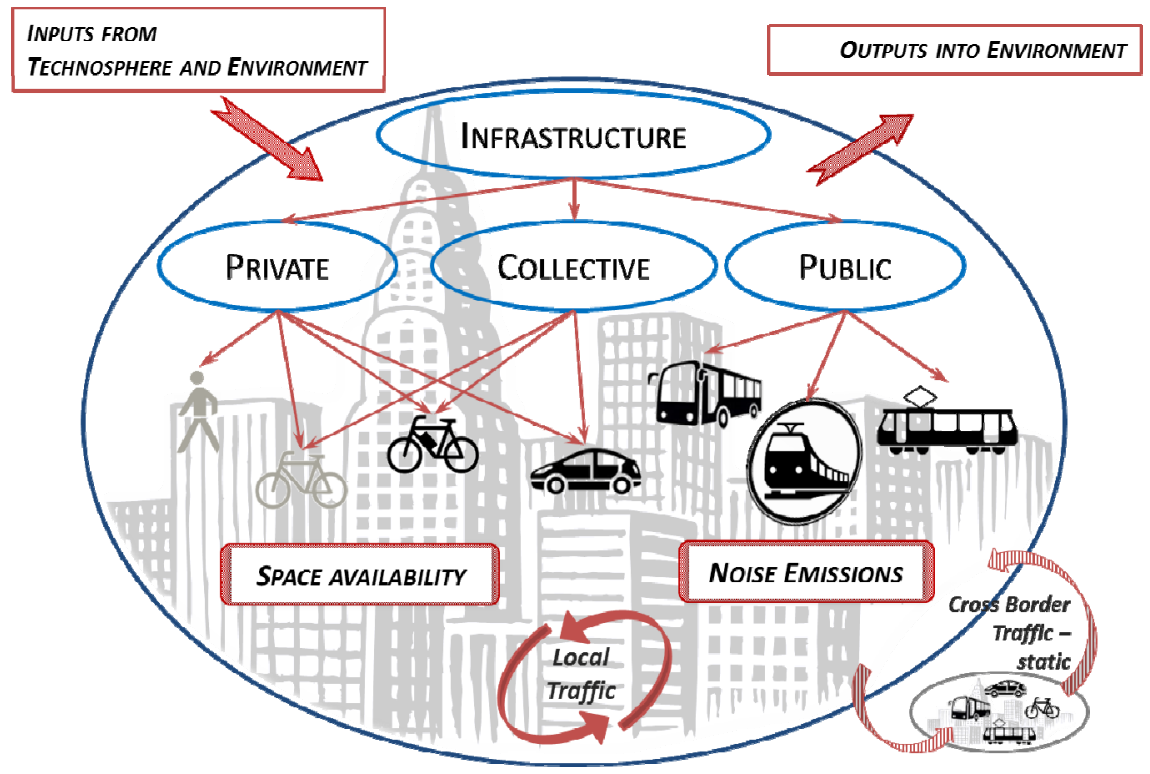

Figure 2: Model of passenger transport in an urban area. For the assessment merely motorized transport will be considered. Traffic across the city's borders (e.g. to other cities) will be considered only statically.

\section{Operationalization}

In order to achieve the goal stated in section 2 several working steps need to be carried out as depicted in Figure 3.

In a first step the current passenger transport situation in the studied urban area will be assessed in a "present scenario". In a second step a baseline scenario for the year 2050 will be created based on a "business as usual" development, i.e. some technological and behavioral changes with regard to the current state will be included, however no major changes will be included in this baseline scenario. In a subsequent step a number of alternative future scenarios will be developed. These may be divided into three general categories resulting from the three key components of sustainable transport as depicted in Figure 1. Following this scheme the effects of an extensive (1) technology change, (2) modal shift and (3) transport avoidance will be assessed in different scenario groups. For each of these transport sustainability components key indicators have to be determined and their possible developments assessed in the future projections.

Based on this, individual and subsequently combined scenarios may be formulated and assessed. In the following chapters the approach and methodological background will be explained in more detail. 


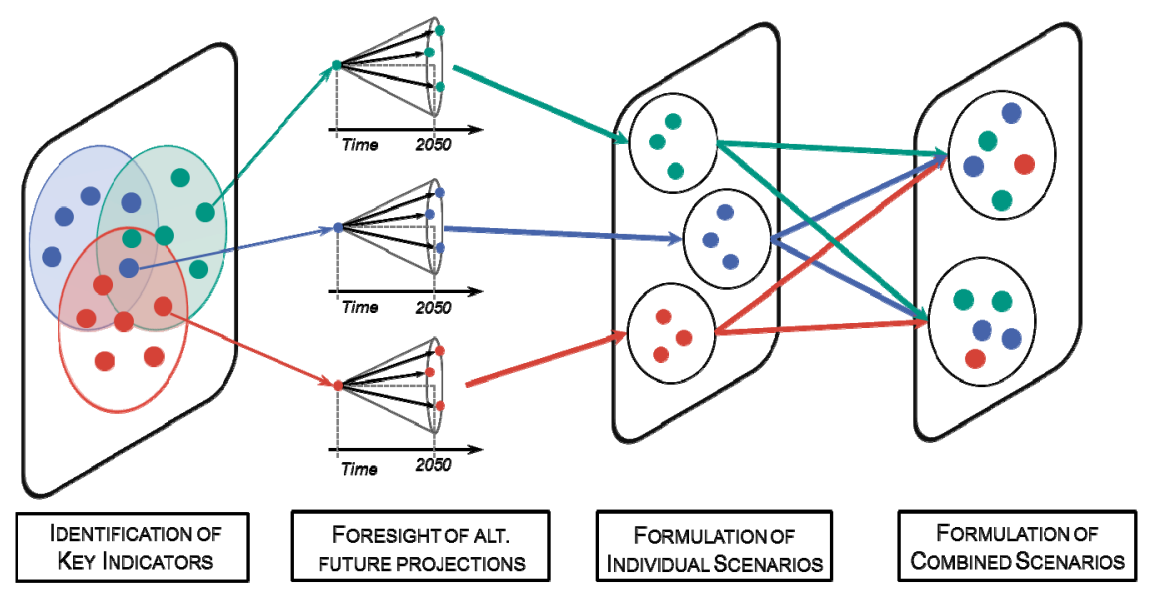

ANALYSIS, MAPPING INTERPRETATION OF SCENARIOS

Figure 3: Working steps of the sustainability assessment of urban transport. Altered, based on [14].

\section{Areas of sustainable passenger transport in the urban area}

\subsection{Technological improvements}

Although fossil fueled vehicles with internal combustion engines are by far dominating the transport sector as of today already a great variety of technologies exists combining vehicle types, propulsion systems, energy storage devices as well as fuel types as depicted in figure 4. Within some of these segments again a large variety with very differing characteristics may be found, such as different types of batteries for electric vehicle application (Li-ion, Li-sulfur, Li-air, etc.) or various types of vehicles ranging from micro cars to large SUVs to vehicles using light-weight materials.

To reduce the complexity of the model to a manageable level in this work merely electric propulsion systems using the next generation battery and supercapacitor technologies will be assessed, taking the conventional fossil fueled combustion engine as reference. Based on this the most viable technologies and combinations thereof will be selected in a rather qualitative manner. For example supercapacitors exhibit a large specific power, and very fast recharge rates but low specific energy. Thus, its use may be restricted to mobile applications that allow for a high frequency of recharge. For conventional vehicles that may not have the possibility to recharge very frequently, this technology does not seem to be very suitable. However, it may be very well applicable for buses, where the supercapacitor may be charged at most of the stops while passengers are stepping on or off board, as is already done e.g. in Shanghai [15]. 


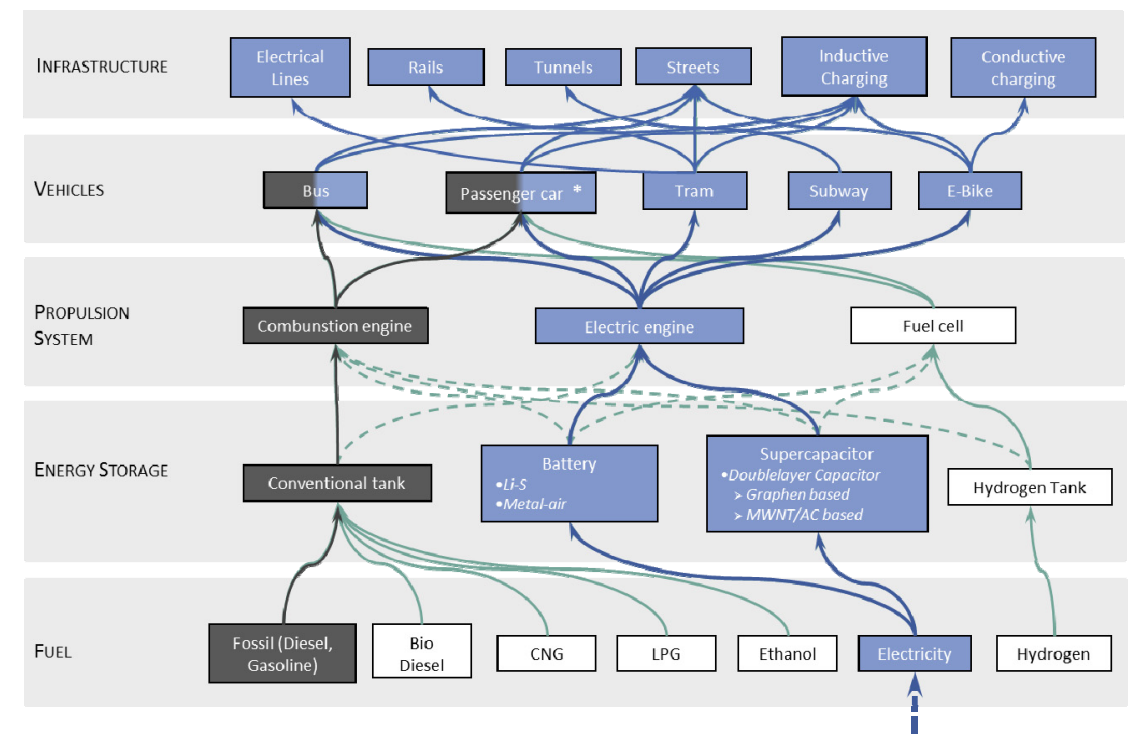

Figure 4: Overview of combination possibilities of vehicles, propulsion systems, energy storage types, fuels and parts of the necessary infrastructure. Dashed lines depict hybrid options. Boxes and arrows in grey depict the technologies that will be modeled as a baseline, boxes and arrows in blue depict the prospective technologies included in the assessment. Changes in the electricity generation will also be included. *Different types of passenger cars may be included in the analysis, e.g. using lightweight materials for construction.

Since electricity generation plays a major role in the life cycle of electro-mobility, changes in the electricity generation and distribution will also be included in the assessment.

Due to the great variety of passenger vehicles, as stated earlier a selection of vehicles will have to be made in order to keep the system boundaries at a manageable level. Therefore, it may be feasible to focus on 2-3 different types of vehicles representing average types of registered vehicles. Regarding the efforts that are currently being put in the incorporation of lightweight materials in the automobile sector, vehicles constructed of these types of materials, such as reinforced carbon fibers (RCF) may be included. For a prospective assessment in the year 2050 the development of these key factors will be estimated.

\subsection{Modal shift}

The modal split can be viewed as the result of people's choices which transport mode to use in order to fulfill their physical mobility need. There are numerous factors influencing these choices that may be inherent to the trip (e.g. the trip's purpose, its distance, etc.), to personal characteristics (e.g. household structure, 
age, etc.), "structural" characteristics such as the availability of parking spaces at the destination, or availability of other transport modes and finally simply incidental, e.g. weather conditions. Numerous studies have been undertaken in order to identify and model the individual factors, their interdependencies and influence on the modal split, e.g. [16-19].

However, for a first methodological approach, the inclusion of the field of decision choice modeling for the determination of the modal split and its possible shift is viewed outside the scope. Since the project aims at answering the question of how a changed modal split affects the economic and ecological performance of the passenger transport within the given system boundaries solely and in combination with technological improvements and transport avoidance, the question of why the modal split changed is not at the core of the work and therefore will not be answered here.

Instead, an approach is taken, where the segment of decision choice analysis is treated as a sort of black box, i.e. the modal shift will be included in a rather generic manner, where qualitative predictions of the development of the modal split may be translated into a quantitative modal split, e.g. [20, 21].

\subsection{Avoidance}

As mentioned earlier, transport avoidance may be achieved via avoidance of physical travel or the reduction of travel distances. The latter includes the use of ITS and urban planning of building infrastructure. In order to respect the integrated life cycle thinking the ITS applicable in the urban area will be included into the system boundaries of the study. Since, however, the inclusion of the building infrastructure is not the scope of the thesis merely the possibly reduced travel distances will be included leaving out the building infrastructure as such.

Information and communication technology (ICT) such as tele-working, tele-communication and tele-shopping may readily be used for shifting physical transport to "virtual" transport. However, from an integrated life cycle point of view the application of these IC technologies introduces some difficulties with respect to system boundaries, as the portion of ICT used for the shift from physical to "virtual" travel should be included in the analysis. Furthermore, tele-shopping induces freight transport causing a shift from passenger transport to freight transport which also should be accounted for. Due to the various uses and very high abundance of ICT it is fair to assume that the portion of ICT that can be allocated to the shift of physical to virtual traffic is rather marginal, and may not appreciably affect the overall results of the study. Therefore, the ICT as such will remain outside the system boundaries; thus the study will merely include a possible decrease of physical travel due to ICT.

Shopping activities however, cannot be treated this simply as additional freight transport is induced while passenger transport is decreased due to the delivery to one's home. Therefore, the marginal freight transport induced by additional shopping activities will be included into the study. This may be done using a "basket" approach. Here the magnitude of the shift from "real" to "virtual" shopping will have to be estimated, e.g. based on the content of an 
average online shopping basket. From this the freight transport additionally induced by this shift may be estimated. This increased freight transport will then be included as marginal freight transport into the system boundaries.

\section{Methodological considerations}

Scenario modeling for the assessment of (predominantly) air pollution of the transport sector has already been performed by various authors, such as the "Clean Transport Systems Study" by the European Commission [22] and the special report on emission scenarios (SRES) by the International Panel on Climate Change (IPCC) [23], which is often used as a basis for scenario building in further studies. Numerous further studies were conducted in this field, e.g. [24-26] however, the vast majority of these type of studies (including all of the referenced works above) are on a global level including very general development paths, e.g. towards e-mobility or towards hydrogen based mobility. As the presented approach includes merely electrochemical storage systems it regards only the development pathway of e-mobility. However, given the lead questions for this assessment as stated in section 2 the scenarios provided by the above mentioned sources are much too broad, as this assessment is operating on a local/urban level and includes soft factors which are predominantly reflected in (2) modal shift and (3) avoidance.

Therefore, own scenarios will be developed based on the input parameters described previously following the work flow depicted in Figure. Since the number of input parameters will be very large and their prospective development causes an unforeseeable number of possibilities only a number of selected important changes can be included in the respective (sub)-scenarios. Furthermore, the interaction of the three areas of technology improvement, modal shift and avoidance has to be identified and included into the model in order to develop the integrated scenarios. In order to manage the great number of factors and their interactions the iModeler or Cross Impact Balance (CIB) may be applied so as to define a manageable number of consistent scenarios.

The environmental performance of the studied urban transport system will be assessed using Life Cycle Assessment (LCA), while the economic performance will be assessed using Life Cycle Costing (LCC). Since noise disturbance and space availability are also crucial factors of urban transport these two indicators will be specifically included into the assessment and thoroughly evaluated and analyzed on the life cycle inventory (LCI) and life cycle impact assessment (LCIA) level, using [27] as the basis for the inclusion of noise as an impact indicator.

The functional unit, to which all environmental burden and economic expenditures will be accounted to, is to depict the daily mobility need of the chosen urban area; i.e. all $\mathrm{km}$ traveled with various means of transport within the urban area. In order to provide a more detailed analysis for the individual technologies the reference flow may be altered to e.g. $1 \mathrm{~km}$ driven with a specific transport mode. In that way a direct comparison of the technology and its best fitting application in the transport mode may be obtained. 


\section{Discussion and outlook}

Based on the presented approach it is the aim to develop a more integrated kind of assessment in order to understand how the three components (1) technological changes (2) modal shift and (3) avoidance contribute to a more sustainable passenger transport in an urban area solely and in combination. The findings may thus provide urban transport planners and managers as well as technology developers with supporting information for their work. However, the presented approach has an important limitation, as merely electrochemical storage systems are included, while e.g. fuel cell vehicles are neglected.

Consequently, the presented approach and following analysis may provide possible pathways towards an environmentally and economically more sustainable passenger transport in an urban area within the development pathway of electro mobility.

\section{References}

[1] "Reducing emissions from transport - Policies - Climate Action European Commission.” [Online]. Available: http://ec.europa.eu/clima/ policies/transport/index_en.htm. [Accessed: 18-Oct-2012].

[2] European Environmental Agency, "Laying the foundations for greener transport - TERM 2011: Transport indicators tracking progress towards environmental targets in Europe", Copenhagen, EEA Report No 7/2011, 2011.

[3] Z. Ross, I. Kheirbek, J. E. Clougherty, K. Ito, T. Matte, S. Markowitz and H. Eisl, "Noise, air pollutants and traffic: Continuous measurement and correlation at a high-traffic location in New York City", Environ. Res., vol. 111, no. 8, pp. 1054-1063, Nov. 2011.

[4] R. W. Allen, H. Davies, M. A. Cohen, G. Mallach, J. D. Kaufman and S. D. Adar, "The spatial relationship between traffic-generated air pollution and noise in 2 US cities", Environ. Res., vol. 109, no. 3, pp. 334-342, Apr. 2009.

[5] T. Tsekeris and N. Geroliminis, "City size, network structure and traffic congestion", J. Urban Econ., vol. 76, pp. 1-14, Jul. 2013.

[6] C. G. Pooley and J. Turnbull, "Coping with congestion: responses to urban traffic problems in British cities c. 1920-1960", J. Hist. Geogr., vol. 31, no. 1, pp. 78-93, Jan. 2005.

[7] B. Nykvist and L. Whitmarsh, "A multi-level analysis of sustainable mobility transitions: Niche development in the UK and Sweden", Technol. Forecast. Soc. Change, vol. 75, no. 9, pp. 1373-1387, Nov. 2008.

[8] D. Xenias and L. Whitmarsh, "Dimensions and determinants of expert and public attitudes to sustainable transport policies and technologies", Transp. Res. Part Policy Pract., vol. 48, pp. 75-85, Feb. 2013.

[9] J. Schippl, "Urban Transport", ITAS, Karlsruhe, Scoping Report, Oct. 2012. 
[10] J. Bilbao-Ubillos, "The costs of urban congestion: Estimation of welfare losses arising from congestion on cross-town link roads", Transp. Res. Part Policy Pract., vol. 42, no. 8, pp. 1098-1108, October 2008.

[11] J. D. Lemp and K. M. Kockelman, "Quantifying the external costs of vehicle use: Evidence from America's top-selling light-duty models", Transp. Res. Part Transp. Environ., vol. 13, no. 8, pp. 491-504, December 2008.

[12] European Conference of Ministers of Transport, Assessment \& decision making for sustainable transport. Paris: The Conference : Distributed by OECD Publications Service, 2004.

[13] J. Schippl and M. Puhe, "Technology Options in Urban Transport: Changing paradigms and promising innovation pathways", ITAS, Karlsruhe, Endbericht, 2012.

[14] S. Brunnhuber, A. Fink and J.-P. Kuhle, "The financial system matters: future perspectives and scenarios for a sustainable future", Futures, vol. 37, no. 4, pp. 317-332, May 2005.

[15] T. Hamilton, "E-Bus 2.1," Technology Review - Das Magazin für Innovation, 20-Oct-2009.

[16] N. J. A. Van Exel and P. Rietveld, "Could you also have made this trip by another mode? An investigation of perceived travel possibilities of car and train travellers on the main travel corridors to the city of Amsterdam, The Netherlands", Transp. Res. Part Policy Pract., vol. 43, no. 4, pp. 374-385, Mai 2009.

[17] R. Buehler, "Determinants of transport mode choice: a comparison of Germany and the USA", J. Transp. Geogr., vol. 19, no. 4, pp. 644-657, Jul. 2011.

[18] G. Santos, H. Maoh, D. Potoglou and T. von Brunn, "Factors influencing modal split of commuting journeys in medium-size European cities", J. Transp. Geogr., vol. 30, pp. 127-137, Jun. 2013.

[19] J. de Dios Ortúzar, Modelling Transport, Fourth edition. Chichester, West Sussex, United Kingdom: John Wiley \& Sons, 2011.

[20] ifmo Institut für Mobilitätsforschung, "Mobilität junger Menschen im Wandel - multimodaler und weiblicher", München, 2011.

[21] ifmo Institut für Mobilitätsforschung, "Mobility Y - The emerging travel patterns of generation Y," München, 2013.

[22] European Commission, "Study on Clean Transport Systems", Final Report, Nov. 2011.

[23] Intergovernmental Panel on Climate Change. Working Group III, Emissions scenarios. a special report of IPCC Working Group III Summary for policymakers. [Geneva]: Intergovernmental Panel on Climate Change, 2000.

[24] M. S. Petersen, R. Enei, C. O. Hansen, E. Larrea, O. Obisco, C. Sessa, P. M. Timms and A. Ulied, "Report on Transport Scenarios with a 20 and 40 Year Horizon”, Copenhagen, Final Report, Feb. 2009. 
[25] H. Turton, "Sustainable global automobile transport in the 21st century: an integrated scenario analysis", Technol. Forecast. Soc. Change, vol. 73, no. 6, pp. 607-629, 2006.

[26] J. H. Ausubel, C. Marchetti and P. S. Meyer, "Toward green mobility: the evolution of transport", Eur. Rev., vol. 6, no. 02, pp. 137-156, 1998.

[27] S. Cucurachi and R. Heijungs, "Characterisation factors for life cycle impact assessment of sound emissions", Sci. Total Environ., vol. 468-469, pp. 280-291, Jan. 2014.

[28] M. Maibach, C. Schreyer, D. Sutter, H. P. Van Essen, B. H. Boon, R. Smokers, A. Schroten, C. Doll, B. Pawlowska and M. Bak, "Handbook on estimation of external costs in the transport sector", Internalisation Meas. Policies Extern. Cost Transp. IMPACT Version, vol. 1, 2008. 